\title{
The Skills of the Students and the Teachers in the 21st Century According to the International Discourse
}

\author{
Vasiliki Polydorou \\ University of Patras \\ Megalou Alexandrou 1, Patras, 26334, Greece \\ Tel: 30- 694- 205- $8294 \quad$ E-mail: polydorouv.kos@gmail.com \\ Zoe Karanikola (Corresponding author) \\ University of Patras \\ Megalou Alexandrou 1, Patras, 26334, Greece \\ Tel: 30- 694- 997- 3053 E-mail: zoekar@upatras.gr \\ George Panagiotopoulos \\ University of Patras \\ Megalou Alexandrou 1, Patras, 26334, Greece \\ Tel: 30-697-266-3858_E-mail: gpanag65@gmail.com
}

Received: February 19, 2021 Accepted: April 15, $2021 \quad$ Published: April 30, 2021

doi:10.5296/ijld.v11i2.18317ＵRL: https://doi.org/10.5296/ijld.v11i2.18317

\begin{abstract}
Following the guidelines of the Agenda 2020, the international Organisations and the European Union have laid the foundations of educational policy. Every person's right to quality education is put forward to every international document, considering education as the means for the prosperity of all the people and the planet. Through qualitative analysis, with the use of thematic networks, three documents: of UNESCO, (2017) "E2030 education and skills for the 21st century", of the OECD, (2019) "future of Education and skills 2030: OECD learning compass 2030" and of the European Commission, (2018). "Annex of the Recommendation for the establishment of a Council regarding the basic skills of lifelong
\end{abstract}


learning", the modern skills required of students as well as teachers are explored, since their acquisition is imperative, as well as the manner of this acquisition are being examined. Thus arose the necessity of acquiring digital and social skills, lifelong learning culture, citizenship and ecology learning. Additionally, the necessity of modification of education is put forward. Finally, it is important that educators receive proper education, so that they acquire new knowledge, attitudes, skills to be able to respond to their role as vehicles of change.

Keywords: Pupil skills, teachers skills, international organizations, agenda 2030

\section{Introduction}

The global community is characterized by successive and rapid changes that have been brought about, mainly by the arrival of the 4th industrial revolution, such as the movement of populations, the increase of life expectancy, they new work models, robotic and artificial intelligence, digitalisation, climate change. The financial challenges in global scale are numerous and for their handling skills are required which will lead the citizens to the path of employability, competitiveness, innovation and prosperity (Karanikola \& Panagiotopoulos, 2019).

The international organizations in cooperation with the leaders of Nations having an understanding of these changes, have prepared the world community to handle jointly and with strategic actions the new facts. Thus, in 2015 the leaders approved the agenda 2030 of the United Nations, setting 17 goals for sustainable development aiming in three aspects for sustainable development: economic, social and environmental. The European Union committed to participate actively in the implementation of the agenda 2030 with specific actions (United Nations General Assembly, 2015).

The 17 SDG (Sustainable Development Goals) are interconnected and aim at the prosperity of mankind and the planet, paying particular attention to equal access of all the women and men to technical and professional training, while as mentioned in the introduction all of that official document of the UN it is of the utmost importance that the governments "provide the adults with skills" (Panagiotopoulos et al., 2019). The 4th Goal of Sustainable Development refers to quality education considering it as the foundation for the Improvement of people's lives and perpetual growth.

\section{Theoretical Underpinning}

\subsection{The Context and Necessity of Acquiring Modern Skills}

The term "skills" is inextricably connected to the ability of humans to survive throughout the ages, to evolve, to incorporate in the social whole, to work and to prosper. In the modern social, economic and cultural environment life skills are a dominant element in a person's ability to live and work. The activation of required skills takes place each time according to the Daily needs and requirements of the individual, so that he can respond to different situations (Javrh \& Mozina, 2018).

According to Panagiotopoulos et al. (2019), skills is one of the important factors connected to the ability of the individual at employability, which is a constant and lifelong a fort of 
acquiring and maintaining a sufficient and suitable employment for the individual. Thus, the skills are defined "as a total of achievements, knowledge and personal characteristics that enable individuals to become employed and successful" (Panagiotopoulos et al., p. 81).

Lynda Gratton (2011), a professor at London Business School, maintains that the future of mankind will be shaped by five forces that are already in development and affect the way we live and will be working in the immediate future. Their dynamic in the global frame create the need for every citizen to become a global citizen rather than local, to examine the historical framework, not only the present framework, to have a broad perspective instead of narrow and short-sighted. The five forces that affect and shape the context are: the power of Technology, the power of Globalization, the power of Demography and Longevity, the power of Society, the power of Energy Resources.

The influence of these global powers in the market is immense and their consequences particularly on the young who enter a volatile labour market, with new challenges and demands that constantly change. Work positions change and some were created recently, while it is highly probable for other means of employability to exist in the immediate future. Today's students may be called upon to claim job positions that are non-existent today. Therefore the ability flexibility and adaptability is necessary and useful, as well as the development of personal identity. Today's youth require not only knowledge but also "a wide spectrum of skills and knowledge and the ability to adjust to change" (Glasbeek, 2017).

In the 21 st century, when the world changes at a frightening rate, societies have turned into one global community, the demand for constant "lifelong" learning constantly increases becomes an acute need and everyone should be "lifelong" learners. Everyone's skills should be updated, so that they are not left behind and let progress bypass them, remaining passive spectators (Laal, 2012).

Furthermore, the vision for an "Educationally Fulfilled Life" requires an adjustment of the educational models and the development of skills, "so that the perpetual progress of learning can function as a generator of employability, success and achievement" (Auger, 2020)

\subsection{Connection Education and Skills}

In the modern socio-economic framework education and training are called to balance social and economic inequalities and to contribute to the economic growth of the individual and of society. Education "can operate as an assisting factor in the creation of luxury conditions, since it relieves more directly from poverty and the disadvantageous conditions under which the citizens live". Additionally, many studies point out the positive relationship between training and the increase of productivity and the improvement of human resources (Panagiotopoulos et al., p. 103).

A substantial share of responsibility for the preparation of tomorrow's citizens through the acquirement of proper knowledge and skills, even from early childhood but also in every educational level, falls onto the state and the educational systems that it shapes. The supply of quality education and of the proper skills he's over are most important for the course of a person's personal and professional life, given that the basis for personal growth are 
introduced during the first stages of education, in early childhood. The need for change of the systems and school programs becomes more intense, since the changes that take place in society and the economy of countries are also intense. Moreover, the environment of a modern classroom is characterized by diversity of students and digitalisation requires new methods of teaching and learning (Glasbeek, 2017).

Perhaps the most important factor of the educational process for the implementation of the current educational policy is the teacher. He operates as the link between theory and practice. Unfortunately, in reality, this practical implementation of theory often has many deficiencies, something predictions and generally problematic situations arise as well as malfunctions, especially during periods of change and reforms in the educational environment. Many times the educator is called to handle these changes and difficulties, not always having the required support of the state. On the contrary, it is considered a given that he has both the required skills and the positive attitude towards impending changes and the scientific training to implement those changes.

In other words, the educator is called upon to become the means of change, a role that often contradicts his "traditional" beliefs, while at the same time he develops a tendency of resistance to change. However, our society has already been characterized as "society of knowledge". Work and working relationships are already affected and are radically changing due to globalization, the huge and constantly growing technological advancement, the overwhelmingly big volume of data and the speed of its transmission (Stamelos, 2010).

Taking all of the above into consideration, and given the fact that, as Coolahan (2002) mentions "educators are in the heart of the educating process and their morality, motivation and skills are of vital importance in a reformation era" (Coolahan, 2002, p. 13), the need for change of the role of the educators as well as the acquisition of new skills is imperative in order to rise to the new challenges of modern society. Of course, this change can take effect neither automatically nor in a short period of time, on the contrary it requires great effort for its acceptance and application, why the involved parties need to be convinced regarding the benefits of the change (Panagiotopoulos et al., 2019).

John Coolahan (2002) points out that the acquisition of the culture of lifelong learning by educators gives a new boost and dynamic to the career of traditional teaching. This new dynamic can help redefine the profession of educator, so that the needs of the society of knowledge can be better served. Since the requirement and the goal of society is to improve the quality of education to create citizens with no skills, who will be creative, flexible, equipped with digital skills, this cannot come into being unless the educators themselves are adequately qualified and in possession of the skills necessary to be creative and innovative, flexible and adaptable.

Fullan (1993), who claims that it is necessary for the educator to be a lifelong learner in order to be efficient, is also moving to the same direction. This will result in him acquiring knowledge and skills, so that he can endeavour to innovate to use new technology and suitable pedagogical methods, to be constantly updated, "to cooperate with others so as to bring about improvements and become a vehicle of change. Systems cannot change on their 
own. On the contrary, the actions of individuals and small groups that work on new concepts cross to produce innovation. New concepts, when mobilized, become the new role models" (Fullan, 1993, p. 17).

In addition, Mezirow's (1990) theory of transformative learning and emancipatory learning states that through the process of critical thinking the individual is driven to the "identification and questioning oval pinions and meanings". Therefore, as Karanikola \& Pitsou (2019, p. 4) characteristically state, "the individual through introspection, acceptance or even questioning of a situation can better understand himself, proceeds to changes, while at the same time, partakes in the change himself in a wider social environment".

Given the fact that the global community is in an "upheaval" which leads to radical changes in multiple levels and in many fields of the society, several nations aspire to respond to those changes through reforms of their educational systems. The adjustment of both schools and educators to these new circumstances is therefore necessary. Social cohesion, competitiveness, employability, social justice, investment in education therefore investment in the young, their knowledge and skills, are considered by the international organizations and the EU to be of the utmost importance (European Commission, 2016).

\subsection{International Organizations}

The international organizations play an active role in the shaping of the educational policy of countries. Especially during the last decade, there has been observed a conformity and convergence regarding the educational vision of the organizations, which actively participate in the international educational framework, towards getting results concerning learning. This common interest mainly pertains to the quality of education, the correct and responsible governing, privatization, the measurement of learning results and their comparative evaluation (Akkari \& Lauwerier, 2015).

The role of international organizations in education is remarkable and essential, since they constitute a basic component in the guidance and definition of the goals of educational policy, by financing the educational systems. Additionally, using their expertise enables them to influence the educational state of being, constituting sources of good educational practices, tools of evaluation of education over policies as well as comparative evaluations (Akkari \& Lauwerier, 2015).

In 2000, the United Nations formulated in writing the program "Millennium Development Goals" (2000 - 2015). A document that set as a primary goal the individual and its development through: a) the provision of basic goods, such as health, education, food, b) the securing of infrastructures and access to water, energy, communication, information c) the respect of human rights such as freedom, equality, acceptance of diversity as well as respect for nature and the development or social responsibility. The program has brought some results, perhaps not the expected ones, and its evolution was the "Agenda 2030- Sustainable Development Goals, SDG" (2015 - 2030). The SDG places particular gravity to human development and links it to work and education. The 17 goals of the Agenda 2030 constitute an "action plan for the people, the planet and prosperity", while the 4th goal refers to 
"securing comprehensive and fair quality education and promoting the opportunity of lifelong learning for everyone". For the first time in 1992, during the International Conference in Rio, Brazil there was mention about sustainable development, which constitutes "the process of constant change and adaptation". Its aim is not only to cover the needs of the current generation but of the future ones as well through the "balanced pursuit of economic growth, environmental protection and social cohesion" (Karanikola \& Panagiotopoulos, 2017).

It is a fact that the international organizations influence and provide guidelines for the setting of goals for the countries' education. Of course, according to the principle of subsidiarity, as it is pointed out in the (Hériard, 2020, p. 1) "the main responsibility for the decision-making concerning educational and training policies lies with each member state, with the European Union operating exclusively in a supportive role. However, certain challenges are common for all nations - the aging of the population, the lack of skills of the workforce, global competition and preschool education - and consequently demand common treatment, with the member nations cooperating and learning from each other".

However, an inconsistency is commonly observed between the theoretical goals of the current educational policy and the expected results which will bring about change. The Greek educational system constitutes such an example, which has included in its goals the cultivation of 8 modern skills, such as "communication in the mother tongue, communication in foreign languages, mathematical ability and basic skills in Science and Technology, digital ability, post cognitive abilities (learning to learn), social skills and skills involving citizenship, initiative and entrepreneurship, cultural conscience and expression" (Pedagogical Institute, 2006, p.3). Despite all this, according to the PISA (2018) results, Greece is ranked below the average of performance in Math, Natural Sciences, Knowledge and Skills of the Global Citizen (IEP, 2019).

Additionally, the Monitoring Report for Education and Training 2019 for Greece pointed out that in Greece the digital school has not been sufficiently developed nor has the development of digital skills for educators been realized as required (European Commission, 2019, p. 8). Among the recent challenges during the covid-19 pandemic that Greek educators had to confront but also in other countries of Europe, was the lack of digital skills so that they could effectively use the platforms of synchronized and unsynchronized education, as well as the difficulty due to lack of experience in creating digital content and the use of effective pedagogical methods in distance learning (CEDEFOP, 2020).

\section{Methodology of Research}

\subsection{Research Objective - Research Questions}

The aim of the current research is primarily to research the primary dimensions of the skills that the school must cultivate and develop in today's students and tomorrow's citizens, in order to enable them to rise to the challenges of the 21 st century according to international dictates.

Secondarily, is the research of the basic dimensions of the skills of modern teachers, as one of the components of change of educational policy and as a configuring factor for the global 
context.

The research questions that composed and eventually configured the research quest of the present research are the following:

- Which set of skills are necessary for the students to develop in order to be able to rise to the challenges of the 21 st Century as tomorrow's citizens?

- Which set of skills must Educators acquire to assist both in the development of skills of their students, as well as the improvement of their personal and professional profile?

- Why is the need to acquire modern skills imperative?

- In what way will the above-mentioned skills be acquired according to international documents and which bodies will assist in that?

\subsection{Presentation of Methodological Tool and Research Material}

For the realization of this research there has been a study of international documents and specifically: UNESCO,(2017) "2030 Education and Skills for the 21st Century", OECD,(2019) "Future of education and skills 2030: OECD learning compass 2030" and European Commission, (2018) "Annex of the Recommendation for the establishment of a Council regarding the basic skills of lifelong learning".

For the examination of the aforementioned research material qualitative methodology with the tool of thematic analysis and thematic networks has been applied. Thematic analysis involves a deductive analytical process (from the general to the specific) and it was developed based on Toulmin's argumentation theory (1958), which aims to provide a structured method for the analysis of negotiating procedures, defining and shaping the characteristics of the arguments connected to the subject under exploration as referred to by Jennifer Attride-Stirling (2001).

According to Attride-Sterling (2001), during the formation of the thematic networks three orders of themes are created: The basic theme is based on and refers to the simpler and more easily visible by the reader characteristics of the data of the research material, while providing some information about the entirety of the text. The organizing theme is a middle-class theme, which organizes the basic themes in similar theme categories. Its composition derives from the deeper understanding of the content of a text through reading it in connection to the other basic themes. The global theme is superordinate and includes the basic idea of the text as a whole.

Thematic analysis and content analysis are used as methods of qualitative approach for the qualitative analysis of texts and beyond. Thematic analysis is a procedure of codification of qualitative information (Boyatzis, 1998) aiming at the understanding of a subject or the meaning of an idea and not the resolution of conflicting definitions of a problem.

Thematic analysis allows the interpretation of many different aspects of a theme, contributes Dwayne essential and in depth examination of the superficial and deeper themes of the document. Furthermore, it allows the researcher flexibility and constitutes a useful tool, by 
providing an insightful, complex and enriched exposition of the data (Braun \& Clarke, 2006).

In addition, thematic analysis, according to Braun \& Clarke (2006), provides basic skills to the researcher which will be useful in many forms of conducting qualitative research and analysis. Therefore it must be evaluated as a fundamental method that the researchers must learn for conducting qualitative analysis. Boyatzis (1998) characterizes it as the tool which can be utilized in different methods, while allowing freedom in interpretation, since the codes provide the capability of referring to many subjects.

\subsection{Creation and Description of Thematic Networks}

During the thematic analysis of the documents for organizational networks were created for the students and correspondingly for the educators. The first thematic Network discusses the type of skills that students/educators must develop, the second thematic Network discusses the necessity of acquiring these skills, the third schematic Network discusses the strategy and development policies of these skills and the fourth thematic Network discusses the institutions of the development of these skills.

It has been established through the thematic analysis of the under research material that the UNESCO (2017:12) document has as its target populations all the citizens, "children, adolescents, adults", also mentioning the "vulnerable populations", and "racial equality" and refers to the skills that they must acquire, not only through standard education, but mainly through lifelong learning and training, something which is predominant throughout the whole document as a primary target and a way of acquiring skills. The OECD (2019:12) document is concerned mainly with the skills that the student will acquire through the educational system, with particular emphasis in standard training but clearly also through lifelong learning. The European Commission $(2018$, p. 1) document has as its target population the citizens and it regards the students as tomorrow's citizens, who, starting from their school life have to acquire modern skills, which must evolve and develop in a lifelong learning perspective.

Undoubtedly, all three documents are in conformity with the 17 SDG which have been instituted by the UN and primarily with the 4th sustainable goal which concerns Quality Education. The right to access to quality and without exclusion education is discussed, linking education to personal, social and global prosperity. In addition, all three documents stress the need for students to acquire modern skills, a need that stems from the global context, as it is has been formulated. Therefore, according to the international documents and answering the corresponding research questions, the following have been asserted:

Regarding the types of skills:

A common parameter is the acquisition of basic skills. In the OECD (2019:49) document the basic skills (writing, reading, arithmetic skill) include the digital skill, as necessary and useful in all levels of communication. Accordingly the UNESCO (2017:43) document mentions the digital skill as a fundamental skill that contributes to the integration of an individual in the society of knowledge, while the European Commission (2018, p. 4-5) document States not only the benefits and the necessity of digital skill but also the correct use of digital 
technology aiming to digital prosperity and cyber-security.

Furthermore, transferable skills, which include business ability, creativity, innovation, communication of ideas, are common in all three documents. It is noteworthy that the business ability is particularly stressed in the European Commission $(2018$, p. 7$)$ document. It is clearly mentioned in the other document but not as a separate skill. A fact that suggests the approach which is more socioeconomic in the European Commission (2018) document. It has also been observed that in the UNESCO (2017, p. 15) document there is specific mention for the need of acquisition of work skills that include technical and professional training.

It must be pointed out here that the UNESCO (2017, p. 16) and OECD (2019, p. 51) documents particularly stress the importance of ecological education and of the protection of the environment, giving in fact ethical dimensions to the issue. In the European Commission (2018, p. 6) document the skill of the citizen and the "knowledge of sustainable systems, particularly of climatic change and demographic change" is mentioned however without paying particular attention to this issue, while it focuses more on the social, economic, political and cultural dimension and the need for citizens' skills.

According to the aforementioned document, citizen skill contributes to the creation of active citizens, who participate and take interest in public affairs and global developments. In the UNESCO (2017, p. 31) document citizen skill is also presented as a contributing factor for the peaceful coexistence of individuals within an undoubtedly multicultural environment. Accordingly, and the OECD (2019, p. 16, p. 104) document citizenship is projected as an important skill for the structuring of a just and viable society.

It is also noteworthy, that in the $\operatorname{OECD}(2019$, p. 93) document, the importance of the health of the body and the spirit through art and creative expression is pointed out as an important component for individual prosperity. Similarly, in the European Commission (2018, p. 8) document the importance of acquiring cultural knowledge and expression through art in education is stressed, something that is lacking in the UNESCO document.

Equally important in all three documents are considered the social skills that include communication and cooperation skills, critical thinking and responsibility, ability of communication and problem solving, empathy and respect for diversity.

Regarding the need of acquiring skills:

A basic necessity of acquiring skills is for them to contribute to the ability of students to rise to the challenge of the 21 st Century. In all three documents the modern skills are considered necessary for the employability of citizens, as the work environment is particularly unstable, volatile and unexpected. This has direct consequences on the economic development of both the individual and society. Also, in all three documents the individual prosperity of the citizens, as well as their ability to actively participate in society operating as global citizens, naturally maintaining their national identity, is emphasized as a goal.

Regarding the method of acquiring skills:

In all three documents, lifelong learning is considered of vital importance for the 21 st century 
citizen, as it provides him with the ability to constantly enrich his knowledge, update his skills, modify behaviors. The educator and his support from the state is put forward as a key role to the process of learning according to the framework of E2030. His constant improvement and evolution through standard education, lifelong learning and training critically contributes to the acquisition of skills.

Something that is considered important is the involvement of students in the program of studies alerting the educators as to what they would like and how to be taught UNESCO (2017, p. 19), as well as the creation of the student agency (OECD, 2019, p. 33-41), who which the students can participate in the formation of the program of studies. The method of evaluation and monitoring of skills exists in all three documents as an important process for their acquisition and for the further development of this procedure. Furthermore, it is put forward the enrichment of the program of studies with the aim of the autonomy of the educator, while the "alliances" of educators contribute to the dissemination of good practices and the exchange of ideas.

Regarding the institutions involved:

The institutions involved in the manner of acquiring skills (International Organisations, nations, educators, society) constitute a common component as well.

Concerning the approach of the documents to the required skills of the educators it should be noted that only in the UNESCO (2017, p. 21-32) document there is particular mention of this matter. In the European Commission $(2018$, p. 10) document there is a reference to the manner of support of the educator, while in the $\operatorname{OECD}(2019, \mathrm{p}$. 37) document the key role of an educator is noted. Clearly, through the study and analysis of the documents it is obvious that all three documents recognize the educator as a basic component in the process of acquiring skills. Specifically, responding to the respective research questions concerning teacher skills the following have been asserted:

Regarding the type of skills:

Digital skills in all three documents are predominant as the most necessary skills for the educator of the 21st century, as they should facilitate and utilize digital technology in learning (UNESCO, 2017, p. 22; European Commission, 2018, p. 10) and digital and data literacy are already considered fundamental skills $\operatorname{OECD}(2019$, p. 49).

The acquisition of the lifelong learning culture by Educators is of vital importance and a requisite for the skills of the 21 st century, as it contributes to personal development, professional empowering and the updating of skills (UNESCO, 2017, p. 22; OECD, 2019, p. 89; European Commission, 2018, p. 9).

Furthermore, all three documents stress the need of acquiring skills of cooperation, innovation, different methods of approach in teaching and learning, evaluation skills.

Regarding the acquisition of skills:

Constant learning and change in the standard education of educators are predominant in all 
three documents as primary factors for acquiring skills (UNESCO, 2017, p. 36; OECD, 2019, p. 23; European Commission, 2018, p. 11), so that educators can receive the necessary support and guidance.

The connection between the educator and the learning process diffuses and is obvious in all three documents. It is considered a condition and prerequisite to educate the Educators in the preparation of today's students, who will become the citizens of the future. Also, the acquiring of skills is considered necessary for personal fulfilment and satisfaction, as well as their professional progress.

Regarding the institutions:

Clearly in all three documents, the International Organizations provide the basic direction and policy-making of educational policy, while the Nations, taking into consideration the International Organizations directives, the European programs, the results of studies of the International Organizations build their own national education policy. The Universities, the community, the businesses, etc, contribute with their cooperation in the development and the reformation of education.

In conclusion, through the thematic analysis of the three documents which constituted the material researched in the present study, the research questions, which had originally been raised and which have already been presented, have been answered.

\section{Discussions on the Results}

From the thematic analysis of the three international documents it is obvious that the development of skills in students, such as basic skills, digital, social, citizen skill, the acquisition of ecological awareness is a requisite and a necessity for the 21 st century, according to the Agenda 2030. The skills contribute to the employability of the individual, to personal prosperity, social and global prosperity. The International Organizations cooperating among them and having the Agenda 2030 as a guide, through their policies aim to a peaceful society that provides equal opportunity to everyone, to a sustainable development, the eradication of poverty, to active citizens with moral thinking and respect for the environment, capable of facing the consequences of the 4 th industrial revolution.

However, equally important and necessary is the need of acquisition of skills by the educators, since the method that the skills of the students will be reinforced and cultivated are incorporated in education. Quality education is the 4SDG and therefore the upgrade of the professional profile of the educator is deemed necessary. In all three documents under research the link between student skills and educators skills was clear. In fact, their standard education and continuing training, integrated in a lifelong learning culture, was apparent and intense as a condition and as an important factor for success.

Furthermore, it is recommended the enrichment and modification of analytical programs, the cooperation among educators as well as with the local and European community, with different institutions, new pedagogical approaches enriched with the use of ICT, attending European programs, such as ERASMUS, e-Twinning etc. 


\section{Macrothink}

Consequently, in order to create today the citizens of 2030 and to "build" the world of the 21 st century according to the vision of the International Organizations a reformation in education should take place, beginning for the most important component of education, the educator.

By the present study it became clear that no educational policy can be successfully implemented, unless its applicators are appropriately trained meaning the educators. As a result, the present study regarded educator as a vehicle of change. In order for that to be achieved, on the one hand he should be sufficiently prepared and on the other he should realize and accept the necessity of change and the responsibility he carries towards society for the preparation of the citizens of the 21 st century. Lifelong learning and training can contribute to that, allowing the educator to develop a culture regarding constant learning and development.

The Greek Ministry of Education and Religious Affairs(2020) has integrated in 218 school units of Primary and Secondary Education, the pilot "Skill Workshops", beginning from September 2020, with the aim to enrich the curriculum and cultivate the proper skills, called "skills of the $21 \mathrm{st}$ century" to today's students. The aforementioned Ministry decision undoubtedly complies to the Agenda 2030 and clearly inspires a sense of hope for the Greek educational reality.

Consequently, a future recommendation for further research on this matter may demonstrate how effective the application of theory to practice will be.

\section{References}

Akkari, A., \& Lauwerier, T. (2014). The education policies of international organizations: Specific differences and convergences. PROSPECTS, 45(1), 141-157. https://doi.org/10.1007/s11125-014-9332-z

Attride-Stirling, J. (2001). Thematic networks: an analytic tool for qualitative research. Qualitative Research, 1(3), 385-405. https://doi.org/10.1177/146879410100100307

Auger, J. (2020).The Future of Lifelong Learning. Education World Forum. Retrieved from https://www.theewf.org/news/2020/new-d21-whitepaper-the-future-of-lifelong-learning-make s-case-for-continuous-skills-development

Boyatzis, R. E. (1998). Transforming Qualitative Information: Thematic Analysis and Code Development (1st ed.). SAGE Publications, Inc.

Braun, V. \& Clarke, V. (2006). Using thematic analysis in psychology. Qualitative Research in Psychology, 3(2), 77-101. https://doi.org/10.1191/1478088706qp063oa

CEDEFOP. (2020, December 15). European skills index. Retrieved from https://www.cedefop.europa.eu/en/publications-and-resources/data-visualisations/european-s kills-index

Coolahan, J. (2002). Teacher Education and the Teaching Career in an Era of Lifelong Learning. OECD Education Working Papers. https://doi.org/10.1787/226408628504 


\section{Macrothink}

International Journal of Learning and Development

ISSN 2164-4063 2021, Vol. 11, No. 2

European Commission. (2016, December 7). Improving and Modernising Education. EUR-Lex.

Retrieved

from

https:/eur-lex.europa.eu/legal-content/EN/TXT/?qid=1481206862153\&uri=COM:2016:941:

FIN

European Commission. (2018, January 17). ANNEX to the Proposal for a Council Recommendation on Key Competencies For Lifelong Learning \{SWD(2018) 14 final\}. EUR-Lex. Retrieved from https://eur-lex.europa.eu/resource.html?uri=cellar:395443f6-fb6d-11e7-b8f5-01aa75ed71a1.0 001.02/DOC_2\&format=PDF

European Commission. (2019). Education and Training Monitor 2019 Greece. Retrieved from

https:/ec.europa.eu/education/sites/default/files/document-library-docs/et-monitor-report-201 9-greece_en.pdf

Fullan, M. (1993). Why Teachers Must Become Change Agents. Educational Leadership, $50(6)$ 12-17.

Retrieved

from

https://www.csus.edu/indiv/j/jelinekd/EDTE\%20227/Fullen\%20change.pdf

Glasbeek, S. (2018). The Importance of Transversal Skills and Competences for Young People. AEGEE Europe. Retrieved from https://www.aegee.org/policy-paper-the-importance-of-transversal-skills-and-competences-fo r-young-people-in-a-modern-europe/

Gratton, L. (2011). The Shift: The Future of Work is Already Here (Kindle Edition).

Hériard, P. (2020, December). Education and Vocational Training. Fact Sheets on the European Union, European Parliament. Retrieved from https://www.europarl.europa.eu/factsheets/en/sheet/139/education-and-vocational-training.

Javrh, P., \& Mozina, E. (2018, February). Life Skills Approach in Europe. European Association for the Education of Adults. https://eaea.org/wp-content/uploads/2018/03/Life-Skills-Approach-in-Europe-summaryEN_F INAL_13042018-1.pdf

IEP. (2019, December). Pisa Survey 2018. Ministry of Education and Religious Affairs. Retrieved from http://iep.edu.gr/pisa/images/publications/reports/2019_12_03_pisa_results_2018.pdf

Karanikola, Z., \& Panagiotopoulos, G. (2017). Human Development and International Organizations: Contemporary Policies and Strategies. International Conference in Open and Distance Learning, 9, 186-195. https://doi.org/10.12681/icodl.1072

Karanikola, Z., \& Panagiotopoulos, G. (2019). Contemporary Digital Skills Development Policies and Adult Education. 10th International Conference in Open \& Distance Learning, 10, 23-32. https://doi.org/10.12681/icod1.2163

Karanikola, Z., \& Pitsou, C. (2019). UN Agenda 2030 and European Union policies to 
promote the right to education and teacher training (full text in Greek). Academia, (16-17), 168-184. https://doi.org/https://doi.org/10.26220/aca.3176

Laal, M. (2012). Benefits of Lifelong Learning. Procedia - Social and Behavioral Sciences, 46, 4268-4272. https://doi.org/10.1016/j.sbspro.2012.06.239

Mezirow, J. (1990). Fostering Critical Reflection in Adulthood: A Guide to Transformative and Emancipatory Learning (1st ed.). Jossey-Bass.

Ministry of Education and Religious Affairs. (2020). Immediate Implementation of the School Upgrade Law. Retrieved from https://www.minedu.gov.gr/news/45521-26-06-20-amesi-ylopoiisi-tou-nomou-gia-tin-anavat hmisi-tou-sxoleiou.

OECD. (2019). OECD Future of Education and Skills 2030. OECD Learning Compass 2030. Retrieved from http://www.oecd.org/education/2030-project/teaching-and-learning/learning/learning-compas s-2030/OECD_Learning_Compass_2030_Concept_Note_Series.pdf

Pedagogical Institute. (n.d.). Detailed

Curriculums. http://www.pi-schools.gr/paideia_dialogos/analitika-programata.pdf

Panagiotopoulos, G., Karanikola, Z., \& Konsolas, M. (2019). Skills: A path to Employability and Prosperity. Policies of the European Commission. In Human Resources Development. Training and International Policies (pp. 67-79). Gregory.

Panagiotopoulos, G., Karanikola, Z., \& Konsolas, M. (2019). Labor Market and Development: UNESCO research data. In Human Resources Development. Training and International Policies (pp. 103-112). Gregory.

Stamelos, G. (2010). Knowledge society and lifelong learning: contradictions and dead ends. Or the path to social explosion. Retrieved from https://doi.org/https://www.researchgate.net/publication/285926544_Koinonia_tes_gnoses_ka i_dia_biou_mathese_antiphaseis_kai_adiexoda_E_e_poreia_pros_ten_koinonike_ekrexe

UNESCO. (2017). E2030: Education and Skills for the 21st Century. Retrieved from http://www.unesco.org/new/fileadmin/MULTIMEDIA/FIELD/Santiago/pdf/Habilidades-SX XI-Buenos-Aires-Eng.pdf

United Nations General Assembly. (2015). Transforming our world: the 2030 Agenda for Sustainable Development. Retrieved from https://www.un.org/en/development/desa/population/migration/generalassembly/docs/globalc ompact/A_RES_70_1_E.pdf 


\section{Macrothink}

International Journal of Learning and Development

ISSN 2164-4063 2021, Vol. 11, No. 2

\section{Copyright Disclaimer}

Copyright for this article is retained by the author(s), with first publication rights granted to the journal.

This is an open-access article distributed under the terms and conditions of the Creative Commons Attribution license (http://creativecommons.org/licenses/by/4.0/). 